\title{
EVENTFUL CITIES AS GLOBAL INNOVATION CATALYSTS: THE SÓNAR FESTIVAL NETWORK
}

\author{
ALBA COLOMBO* AND GREG RICHARDS† \\ *Arts and Humanities Department, Universitat Oberta de Catalunya, Barcelona, Spain \\ †Academy for Leisure, NHTV, DX Breda, The Netherlands
}

\begin{abstract}
As the economy becomes more globalized, a growing number of events are exerting an influence on activity and innovation globally in different fields. Therefore, we argue that "eventful cities" can act as important catalysts for eventfulness in other places as well. This article analyzes the case of the Sónar electronic music festival, an event that originated in Barcelona, Spain, but which now runs different editions in many cities worldwide. This empirical study of the innovation capacity of a cultural event examines how a locally based music festival has transformed itself by using the global "space of flows" to influence the local "space of places.” The Sónar Festival has turned itself into a relational hub in a global cultural network, using stylistic innovations to link geographically dispersed nodes in order to create new products, open up new markets, and strengthen its own position as a global source of eventfulness.
\end{abstract}

Key words: Eventful cities; Festivals; Innovation; Space of flows; Space of places

\section{Introduction}

The global proliferation of events and event forms has been stimulated in recent decades by processes of economic and cultural globalization. Not only have economic systems become more integrated, allowing for the transmission of economic configurations from one region to another, but global networks also support the globalization of culture. Nijman (1999) argued that the process of "cultural globalization" parallels economic globalization as "an acceleration in the exchange of cultural symbols among people around the world, to such an extent that it leads to changes in local popular cultures and identities” (p. 148).

Events have become an important channel for such exchange of cultural symbols at global level, with sporting events such as the Olympic Games, cultural events such as the European Capital of Culture, and business forums such as the Cannes Film Festival helping to generate and circulate symbolic value. In doing so, many of these events help to configure the fields in which they operate (Lampel \& Meyer, 2008). Such "field configuring events" 
(FCE) can provide a source of eventfulness in the cities in which they originate, but they can also influence other cities that mimic, copy, and borrow event ideas and formats.

This article considers how a single event developed in one city can be a source of global as well as local eventfulness, shaping not just the eventful city in which it originated, but also by stimulating event innovation at a global level.

\section{Globalization, Events, and Innovation}

As major cultural and economic configurations in contemporary society, events and event forms have been subject to processes of globalization. For example, Ferdinand and Williams (2013) examined the diffusion of Caribbean carnivals around the world. They argued that such festivals can be seen as a form of export product, because marketing is conducted in foreign markets, while production is based in the home country. They described the development of Trinidadian carnivals as an export product in terms of an evolutionary path from exports to developed countries (Europe and North America), which then stimulated further government-sponsored development of the carnival product across the Caribbean, in turn leading to more sophisticated development of Caribbean carnivals as an "export product" for developed markets. Finally, the new Caribbean carnivals have in turn begun to reproduce versions of themselves in developed markets. Therefore, we see an interactive process of export product development and feedback into the home market that gradually changes the economic and cultural form of the event itself. Similarly, Crespi-Vallbona and Richards (2007) have shown that the interplay between local and global cultural flows can produce new and innovative cultural forms.

The idea that global flows of culture are mediated and changed by local culture is taken up by Czarniawska and Sevón (2005), who saw "the traditional explanation of the circulation of ideas, objects, practices, customs and even institutions” (p. 7) as a process of diffusion. They also introduced the notion of translation, which suggests the localized adaption of cultural forms by local cultural intermediaries who imitate desires and beliefs, translation ideas, objects, and practices for their own use.
Such ideas underline the recursive flows of ideas and culture through global and local networks. In particular, the work of Castells (2009, 2010) highlighted the differences between the flows of culture through global networks of finance and the media in what he called "the space of flows" and the localization of culture in the everyday world, or what he calls the "space of places." The important point that Castells made is that local places gain power by being well connected to the global "space of flows," and that the global flows of culture are in turn transformed by their concrete use in the "space of places." This is a more explicit formulation of the process of "glocalization" identified by Robertson (1990). In Castells' model, an important mediation role is played by "switchers," or key actors, who are able to link different global and local networks. At a local level the work of "programmers," or individuals dealing with local cultural networks, is seen as important in translating the flow of ideas into concrete cultural products. For Castells, flows of power in this system are predominantly from global to local contexts, although he does see the potential for local resistance and creativity as well, most notably in his more recent work on global protest movements (Castells, 2012).

Castells' ideas represent an interesting model of cultural and economic globalization, showing how cultural forms and content are propagated and transformed. However, Castells himself puts little flesh on the bones of concepts such as switchers and programmers, and gives no concrete examples of how these actors work to articulate global and local culture. Most attempts to develop more detailed models of the articulation of global and local cultural forms have been undertaken as case studies of individual cities. For example, Cohendet, Grandadam, and Simon (2010) analyzed the flow of cultural concepts in the city of Montreal, illustrating how global operators such as Cirque du Soleil act to link different levels of cultural actors with global cultural networks. Hardbord (2002) also analyzed film festivals, such as Berlin Film Festival, as a media events and nodal points on the circuit of cultural flow, mediating the relationship between the local and the global film industry. In Barcelona, Rovira (2010) analyzed the role of switchers in linking particular networks in the design field with the global space of flows. 
These studies seem to indicate that power in networks lies in the ability to direct flows of information and resources between global and local networks. Those in key positions in the network (the "switchers" in Castells' terminology) are able to capture and utilize global information to identify and steer new cultural trends that can lead to local innovations. In the innovation literature there is also a growing realization that innovation often takes place within networks. Fagerberg (2003) stressed that firms do not innovate in isolation but rather depend on extensive interaction, and so understanding the innovation process requires an analysis of "systems" or "networks."

Bathelt, Malmberg, and Maskell (2004) understood innovation as a part of an integrative process where actors who possess different types of knowledge exchange information in order to solve a concrete problem. The type of knowledge involved varies for local and global actors. They stressed that "the more codified the knowledge, the less spacesensitive should these processes tend to be” (p. 2), and if the knowledge involved is diffuse and tacit, the argument is that "such interaction and exchange is dependent on special proximity between actors" (p. 2). They also highlighted the conditions under which knowledge can be exchanged between actors embedded in a community, what they called "buzz," and by selecting providers outside the local milieu, or what they called "pipelines.” This underlines the importance of local and global relationships and knowledge exchange in innovation processes.

More recently, Martin and Moodysson (2010) explored the organization of innovation processes with a specific focus on the geographical distribution of knowledge networks and the distinctive nature of knowledge flows in symbolic industries. They found that the knowledge sources in geographic proximity are predominant, even though traditionally it is considered that creative or symbolic industries are highly dependent on inputs from nonlocal knowledge sources. This underlines the important role of local intermediaries in ensuring the penetration of global ideas and innovations.

The role of knowledge flows in the innovation process is also emphasized by Wijnberg (2004), who outlined the way in which innovations are selected. For example, Wijnberg (2004) argued that a "stylistic innovation" is "something new presented in a way that the value will be determined by the 'selectors'” (p. 1416). Selectors may be consumers or intermediaries, but in either case the flow of information is vital for the selection process, because an innovation must be a "product or a characteristic of a product, which is recognized by the relevant selectors as a new and legitimate response to a set of preferences” (p. 1416).

Tran (2010) analyzed the way in which such selection processes work in the creative industries, where innovation is based on style and fashion. For Tran (2010), stylistic innovation deals with "the changes in aesthetics through changes in looks, shapes, forms and changes in symbolic value expressed through new meaning and language of products” (p. 133). The idea of stylistic innovation involves three main dimensions: 1) symbolic value, 2 ) the construction of symbolic value through intersubjectivity, and 3) timing. Tran also argued that stylistic innovation mediates between social trends, subjective evaluation, and feelings attached to the style, and therefore it is an intersubjective construct. The right timing is also essential, to identify the right moment for innovation, anticipating social change, and recognizing that style "is subject to the transformation across time and space" (Tran, 2010, p. 134).

The rise of the cultural and creative industries has placed more emphasis on intangible content and style in the innovation process. Potts, Cunningham, Hartley, and Ormerod (2008) talked about the creative industries themselves as a network, "the creative industries are the set of economic activities that involve the creation and maintenance of social networks and the generation of value through production and consumption of network-valorised choices in these networks" (p. 10). In terms of the stylistic innovations that are mediated by selectors (Wijnberg, 2004), this indicates that specific places may be particularly significant in creative innovation processes, because they are able to generate face-to-face interaction in the social interaction that underpins the creative industries.

Therefore, in the current competitive, globalized economic environment, places need to ensure that they become sites in which the selection system is organized and controlled. It is important for cities to develop a "hub" role in knowledge networks, where flows of knowledge and selectors converge. 
In these hubs, selectors come together and engage in proximate processes of knowledge exchange in order to determine the value of stylistic innovations. In contrast, other locations simply act as "nodes" in global networks, which are the receptors of knowledge created elsewhere.

In the case of Barcelona, it is clear that the local context has had an important influence in shaping the Sónar Festival, Barcelona's International Festival of Advanced Music and New Media Art, (Sónar from now on) around the world. This event has in turn had an influence on other music festivals, and the format has been copied or mimicked in many different ways. The festival emerged after the 1992 Barcelona Olympics, a moment at which the city suffered from a "cultural vacuum," when the economic, political, and creative effort of staging the Games led to a subsequent lack of investment and energy for new projects. Sónar helped to provide cultural product to fill this vacuum and to animate a newly developed area of the city center.

In this article we consider how Sónar as a locally based festival has turned itself into a model for the electronic music scene globally by ensuring a process of stylistic innovation in which locally generated tacit knowledge is abstracted and globalized through a selection system. In this system, the Barcelona Sónar Festival has come to function as a hub within a global network of creative nodes, which gives shape to processes of stylistic innovation and dissemination. In this sense, Sónar is not just a source of eventfulness in its home city of Barcelona, but also a source of ideas for aspiring "eventful cities" around the world.

\section{Methodological Approach}

\section{Research Setting}

The proliferation of cultural event formats has not received much attention in the literature, although there are some recent studies relating "field configuring events" (FCE) with creative products and creative fields (Anand \& Jones 2008; Anand \& Watson 2004; Schüßler \& Sydow 2013). However, with the global growth of the cultural and creative industries (UNESCO, 2013) and the increasing importance of cultural signs in the symbolic economy (Lash \& Urry, 1994), cultural events are becoming more central to the global "space of flows"
(Castells 2009, 2010). Therefore, we view cultural events as a suitable context for studying stylistic innovation because: 1) culture is circulated in the global "space of flows" and at the same time is transformed by the influence of the local "space of places" (Castells 2009, 2010); 2) cultural events are usually linked to the place where they occur, and at the same time operate within global networks of culture; 3) cultural events deal with intangible culture and creativity, enabling them to generate rapid circulation of information and ideas; and 4) cultural events usually have a clearly identifiable group of selectors, switchers, or programmers responsible for the cultural content and/or attracted by the programming of the event.

\section{Research Design and Analytical Approach}

The explorative research approach of this study is based on a single case study (Yin 2004). The case study method not only allows us to explore festival, but also to identify the relationships between global and local cultural flows (Castells, 2009, 2010).

Therefore, we selected our case study on the basis of the following criteria: 1) it should be an event with popular culture content (as this is arguably more universal than most forms of high culture); 2) it should be an international event with editions in different countries and with international artists in the program that stimulates the circulation of cultural content and ideas; and 3) an event that has had sustained success over several years, in order to reveal longitudinal trends in innovation. The selected event is an electronic and dance music festival established more than 20 years ago, which has now developed around the world with international and local artists, having significant audience participation.

The research question that we address in this article is: How can a field configuring event act as a stimulus for event innovation in cities? In answering this question, we concentrate on the role of Sónar in organizing the selection processes necessary for stylistic innovation and in organizing the field of eventfulness at both global and local levels.

\section{Data Collection}

The case study relies on two main data sources, collection of primary data through semistructured 
in-depth interviews and analysis of archival data as Lampel and Meyer (2008) suggested. Data from different editions of the event around the world were collected from sources including festival programs and other documents such as reports, media coverage, websites, etc.; interviews (undertaken between 2009 and 2013 ); personal presentations, discussions and panels; additional reports; and media reviews, among others.

Interviews were held with three main groups of programmers, switchers (Castells, 2009, 2010), and selectors (Wijnberg, 2004); 1) location-related stakeholders, journalists, local artists, and programmers; 2) international professionals, such as festival organizers, buyers, and programmers; and 3) national and international festival consumers. A total of 34 interviews were collected, distributed across each of the three groups (Table 1).

As has been pointed out before, we complemented the interview data with a wide range of documents and achieve material and data from different international editions of the festival. We gathered these data through our interviews with managers and festival participants and analysis of different publications and media.

\section{Data Analysis}

This festival was subject to in-depth analysis guided by the research question. Therefore, to be able to answer the question, the goal was to map out the important of the initial festival in Barcelona, articulated as a hub, connecting different nodes around the world. Complete transcripts of the interviews were made, and these were first subject to open coding to identify concepts and categories in the data, and then axial coding to relate the data to the concepts and categories contained in the theoretical framework. The coded data were then entered into a matrix for analysis (Miles, Huberman, \& Saldaña 2013). The data matrix facilitates the analysis of qualitative data by relating cases and themes within the data collected, allowing relationships between dependent and independent variables to be analyzed.

Because the festival has a substantial longitudinal dimension, given its 20-year history, it was also important to extract a temporal dimension from both the interviews and the secondary documentation. Therefore, the different festival events developed over time have been selected as explanatory cases. The dimensions that were analyzed for the events included the different programing and production models, the scale and dimensions of the event, and their geographic location.

\section{Previous Studies}

Although the dissemination of event formats has not been studied in much detail previously, Lampel and Meyer (2008) established concrete criteria for the identification of FCEs, such as their ability to assemble members of a concrete business sector in one location; their limited duration, running from a few days to weeks; their unstructured and structured opportunities for face to face social interaction (parties and markets); their dependence on dramaturgical activities; their functions in information exchange and collective sense making; and generating social and reputational resources.

One can clearly connect most of these dimensions of FCEs to factors that stimulate innovation, as in the case of the creative industries for example (Potts et al., 2008). However, there is a lack of academic literature about innovation processes in global cultural events. This is perhaps surprising,

Table 1

Characteristics of Interviews

\begin{tabular}{lclc}
\hline Profiles & \multicolumn{1}{c}{ Local } & \multicolumn{1}{c}{ International } & \multicolumn{1}{c}{ Consumers } \\
\hline $\begin{array}{l}\text { Number } \\
\text { Duration }\end{array}$ & \multicolumn{1}{c}{$\begin{array}{c}\text { Between } 30 \text { and } \\
90 \text { min }\end{array}$} & $\begin{array}{l}\text { Between 45 and 70 min (7 int.) } \\
\text { Short interviews between } \\
10 \text { and 15 min (9 int.) }\end{array}$ & $\begin{array}{c}\text { Short interviews between } \\
10 \text { and 15 min }\end{array}$ \\
$\begin{array}{l}\text { Date } \\
\text { Place }\end{array}$ & 2009 and 2010 & 2009, 2010, and 2013 & $\begin{array}{l}2009 \text { and 2010 } \\
\text { Barcelona }\end{array}$ \\
\hline
\end{tabular}


because one would expect major field configuring events to have a role in innovation processes, particularly given their ability to attract and bring together both local and global actors for face-toface exchange.

There is a growing literature on the social, economic, and development impacts generated by cultural festivals (Colombo, 2009; Garcia, Melville, \& Cox, 2010; Getz, 1991; Waitt, 2003, 2008). However, most of these studies concentrate on the immediate, short-term impacts of events, without paying much attention to long-term development or innovation effects. Other authors, such as Evans (2003, 2007), García (2004), and Richards and Palmer (2010) have shown that linking events to urban planning processes can provide a useful tool for urban, economic, and even social development. The convergence between events and urban policies is also evident in Häusserman and Siebel's (1993) identification of the increasing festivalization of urban policies, through the staging of sporadic mega-events, such as World Expos and Olympic Games. Jakob (2012) also referred to a process of "eventification" in cities, as urban consumption and production processes are turned into events.

There is also a growing body of unpublished or grey literature studies on specific events. For example, for the Barcelona Sónar Festival, Oliveras (2008) analyzed the cultural market and local environment of the event, focusing on definition, production values, and future perspectives, while Bernárdez (2011) provided internal structure information and focused on its mission, audience, competitors, and promotion. Sónar has also been analyzed in the context of a European Commission research project (Giorgi, 2010; Magaudda, 2009; Magaudda \& Colombo, 2010) analyzing its history and organization; its sociocultural context; its networking structure; its symbolic representation strategies; relationships with politics and the media; and its audience. This research indicates that Sónar has been very successful in linking local programmers in Barcelona with different global networks that have helped frame the identity and brand image of the festival.

The lack of studies in the field of global cultural events and innovation is surprising. Hence, the present study attempts to analyze how a music festival, such as the Barcelona Sónar Festival, can act as a stimulus for innovation and eventfulness on a global level.

\section{The Sónar Festival: Locally Embedded and Globally Connected}

The Barcelona Sónar Festival is a music festival that takes place annually in the city of Barcelona during 2 days in June. It was founded in 1994, shortly after the 1992 Barcelona Olympic Games, a time when, as Victor Nubla pointed out, "the city faced a 'cultural vacuum' with declining resources for culture as a result of the vast public expenditure on the Games” (personal interview, 2009). During the 3 or 4 years following the Games, Barcelona experienced a period where public support for cultural initiatives declined, while at the same time a new generation of social and cultural projects emerged. One of these projects was Sónar, a platform to promote and consume electronic culture, founded by Sergio Caballero and Enric Palau ${ }^{2}$ (two electronic musicians) and Ricard Robles ${ }^{3}$.

The first edition of Sónar in 1994 was made possible thanks to the support of different institutions, which had specific strategic needs. On the one hand, the Sociedad General de Autores y Editores (from now on $\mathrm{SGAE}^{4}$ ) was attempting to develop a platform for electronic music in Spain, and on the other hand, the Centre de Cultura Contemporània de Barcelona (from now on $\mathrm{CCCB}^{5}$ ), was a local administrative initiative supporting different "underground” cultural projects.

It is interesting to note that the city administration did not identify the festival as an important initiative until 1996. As Ferran Mascarell, a former city culture director pointed out, "the City Council was interested in using the festival to help regenerate certain districts. Sónar met this need by generating significant economic and tourism impacts in two run-down areas of Barcelona, one in the city centre and another one on the sea front" (personal interview, 2009) ${ }^{6}$. In this sense, we can see that Sónar, although originally emerging as an "underground," grass roots initiative, was quickly taken up by the cultural "upperground" in Barcelona (following the terminology for different cultural systems developed by Cohendet et al., 2010).

During the most recent edition of the festival (2013) some structural changes were made, ending 
the long collaboration partnership with the neighboring institutions in the city center, such as museums and cultural centers (CCCB and Museu d'Art Contemporani Barcelona) and moving the event to the city exhibition halls. The increasing spatial distance between the festival and its supporters heralded an end to the local regeneration role of the event, which had been very important for the event and the city in the early years of the festival. One of the reasons for this change was the growing numbers of visitors. This growing popularity created a need to develop new models for Sónar, but the early years of regeneration-based collaboration embedded the event firmly in the local context, or "space of places.”

During its early editions, the festival maintained its original focus on electronic music and gradually became part of a global network of electronic music and culture. Two trends highlight this situation: 1) from the beginning the festival programmed internationally well-known musicians and artists, such as Laurent Garnier (programmed in the first edition, 1994), Richie Hawtin (set in 1996), and Jeff Miles (in 1997) ${ }^{7}$; 2) from the second and third edition, as Teglietti (festival manager) pointed out "the festival audience, as well as accredited professionals, grew from being local and national to being international" (personal interview, 2013). Therefore, Sónar started to be internationally well known as a festival with its specific aesthetics and iconography related to electronic music and electronic culture.

At the same time, Sónar established a unique structure for the festival. Sónar presented different platforms for different music streams, such as experimental and alternative music, as well as a platform focused on electronic and different dance music labels. This division led to the basic and most characteristic structure of the festival, a division between Sónar by Day, and Sónar by Night.

During the day, the festival presented experimental and advanced music from established as well as unknown artists in open-air venues, with a special stage for local and national artists. From 1994 to 2012, this program was staged in the city center of Barcelona in an area surrounded by cultural institutions, which generated a unique atmosphere and identity for the event. However, since 2013 it has been held in the exhibition halls in Plaça d'Espanya. This change perhaps represents a new phase in the development of the festival, once again moving away from its relationship with the public administration of the City of Barcelona and back to a more commercial model. This change has arguably been stimulated by the economic crisis of recent years.

Sónar by Night is where the audience can experience big concerts in huge venues featuring both well-established artists and newcomers. This has been held in different venues and during the last few years, it has been staged in the Barcelona exhibition venues in the neighboring city of Hospitalet. The program consists mainly of three different kinds of artists: 1) famous international artists such as Grace Jones in 2009, or Pet Shop Boys and Kraftwerk in 2013; 2) internationally established DJ's such as Jeff Mills and Laurent Garnier; and 3) established popular acts in the electronic music scene, such as Moderat and Fever Ray, both programmed in 2009 (Magaudda \& Colombo, 2010).

Over the years, Sónar has adapted its specific language and iconography to international trends in electronic music and culture. As Luis Hidalgo, well-known music journalist, explained, "the festival has focused its aesthetics on an ambiguous concept so that could be adapted to the trends of new times" (personal interview, 2009).

With this goal, Sónar established itself in the global culture network with a clear and specific identity, as a summer festival in a sunny Mediterranean European city where the latest trends in music, culture, and art can be discovered. As one of the directors, Enrique Palau, pointed out, "from the first edition the festival had been an international event and had a clear international projection with artists, audience and professionals from all over the world" (personal interview, 2010). At the same time, the festival presents itself to the local audiences and music scene, as a well-connected and internationally recognized music festival with a special focus on the latest international trends. Both positions give the festival a particular status, which from the beginning makes it locally, nationally, and internationally different.

The Sónar festival has developed different innovation strategies over the years, all of which rely on transforming the international links developed through the festival into an established network of collaboration. The festival has been adapted and 
cloned as Ricard Robles (one of the directors) notes, "the high quality of art direction, event format, characteristics, sound level standards and technical equipment has branded itself” (Bernárdez, 2011). This process has taken several years and involved many different products and prototypes, such as the Taste of Sónar and SónarSound.

For the festival organizers, A Taste of Sónar is basically an "appetizer" early in the year, before the Barcelona festival. These presentations generally last a maximum of 2 days, and give a possibility to present artists and performances framed within the Sónar brand. This format offers a reduced version of the festival in Barcelona to the local audience. Hence, this kind of presentation could be seen as a promotional strategy, designed to engage with an audience "which later may be at the festival in Barcelona and professionals gather too, and they are going to be talking about Sónar for a while, developing promotion for the festival in Barcelona” according to Ricard Robles (Bernárdez, 2011). Similar "tests" have been presented during the last decade in London, Cape Town, and Osaka, as well as other cities.

On the same basis, the organizers programmed SónarSound, a large version of the festival staged in cities around the world. Normally longer than the Taste, this model has different formats, depending on the city where it is held. For example, in Seoul (2006) it was an exhibition with some performances, whereas in São Paulo (2004) it has had practically the same format as the Barcelona event. After the first successful export initiatives in 2002, with London, Hamburg, and Tokyo, the festival organizers had a rush of demands from different cities to export the festival around the world. At that point the organizing company, Advanced Music S. A. (from now on AM) realized that they had created a brand that "has a power alongside the artists. Actually, when someone calls us they do not want us to program well-known artists, because the professionals trust the power of the brand," noted Ricard Robles (Font \& Salat, 2007).

After 20 years, and with much experience of the international scene, the festival now sees itself as a global event, taking place in different cities around the world with different formats. As can be seen in Table 2, the festival has exported its model to 24 different cities, returning to five of these to present the festival several times.

Observing the evolution of different presentations of the festival around the world, it seems that London, Hamburg, and Tokyo are the cities where the festival has been presented on a more or less

Table 2

Presentations of Sónar Festival Around the World

\begin{tabular}{ll}
\hline Location & \multicolumn{1}{c}{ Year } \\
\hline London & $2002,2003,2004,2005,2009,2010,2011,2012$ \\
Lisbon & 2002 \\
Neuchatel & $2002,2003,2004,2005,2006$ \\
Hamburg & $2002,2004,2006,2011,2012,2013$ \\
Tokyo & 2003 \\
Rome & 2004,2012 (2013 planned but cancelled) \\
São Paulo & 2004 \\
Lyon & 2004 \\
Guadalajara & 2006 \\
Buenos Aires & 2006 \\
Seoul & 2007 \\
Frankfurt & 2009 \\
Washington & 2009 \\
New York & 2010,2012 \\
Chicago & 2012 (2013 planned but cancelled) \\
Cape Town & Chicago, Toronto, Montreal, Boston, Denver, \\
Sonar North America Tour 2012 & Oakland, Los Angeles \\
Reykjavík & 2013 \\
Osaka & 2013
\end{tabular}

Source: Sónar website and reports. 
continuous basis. Other cities such as São Paulo, Chicago, and Cape Town are locations where the festival has tried to develop regular collaboration, although sometimes this has not been completely successful.

Although as Georgia Taglietti pointed out, "different contexts make the festival presentation possible” (personal interview, 2013), even the adaptation of the festival in different countries has been complex. During their global expansion, AM lost interest in exporting to the rest of Europe, because as Taglietti commented, "the audiences in Europe are already the ones going to the main festival in Barcelona” (personal interview, 2013). Therefore, more events in Europe might detract from the Barcelona event by attracting the "selectors" (both professionals and audiences) to other locations.

This kind of exporting activity would not be possible without a clear strategy and process, as well as the local Barcelona context where AM developed these festivals and the content. The most important success factors in the export model seem to be established local partnerships able to support the festival in different locations on a regular basis; and to be present briefly in other locations to expose the festival brand around the world.

These observations seem to indicate that Sónar is a cultural event with a specific form and content, globally connected as well as local embedded. Over the years, Sónar has transformed itself into a global platform capable of connecting the "space of places" and the "space of flows" (Castells, 2009, 2010) of electronic music and culture, invading the global sphere with local content. We would argue that the festival connects the electronic music field at a global level by plugging it into different local contexts.

\section{Sónar as a FCE and its Stylistic Innovation Role}

Having outlined the general characteristics of the festival, the following sections concentrate on the development of Sónar as a FCE and its role as an innovation hub.

\section{The Festival as a Field Configuring Event}

Looking at the FCE criteria identified by Lampel and Meyer (2008), it seems that the Sónar festival connects members of a concrete sector in a platform (not just in one place and time but in several places at different times); but generally its duration is limited; it provides opportunities for face-to-face social interaction (parties, markets, etc.); it depends on dramaturgical activities; it is an occasion for information exchange; collective sense making; and it generates social and reputational resources.

Therefore, we argue that Sónar could be considered as a FCE for the electronic music sector, which innovates based on locally embedded knowledge, and uses a web of relationships to project the event globally. Considering that FCEs encapsulate and shape the development of professionals, technologies, markets, and industries (Lampel \& Meyer, 2008), it could be argued that the relationships Sónar generates through its exporting activities may constitute an innovation system that encourages the global development of the electronic music sector. This in turn helps to ensure the continued dominance of the Sónar event as a hub in the electronic music network worldwide.

For example, the well-known French musician and producer Laurent Garnier noted that "the professionals and artists need to be at the Sónar festival to know what's happening in the music wise, when the brand goes big and strong and crosses frontiers, the people talks about it, and the organizers bring different things to different places" (personal interview, 2010). With this comment, the artist suggests two general ideas: 1 ) the festival is a platform where the professionals need to be in order to know what is happening in the field, and 2) that the festival organizers import and export artists and performances to different places around the world.

As a platform for professionals, the festival has developed a leading edge program that supports its reputation for innovative leadership. As Ben Osborne, a professional music journalist from the magazine DJ, commented “even if I'm working in the field and I usually receive new material from diverse artists, the Sónar people always get some performances and artists that are new for everyone" (personal interview, 2010). Therefore, it could be considered that the festival has the possibility to present new artists and ideas to the electronic music scene.

In terms of export development, the well-known DJ and producer Jeff Milles commented, "the 
festival organizers travel all year round to find new artists and musicians to bring them to the festival" (interview, 2010). That also suggests that the festival organizers work hard on updating the content by researching new influences, performances, and artists to present an interesting program. This brings AM in contact with the international artists, producers, and agents who come to Sónar from around the globe, as well as being able to present new artists to different locations.

As indicated above, FCE's support the formation and the stabilization of networks. Even though they take place in one particular location, the Sónar events are related directly with the global initiative, transforming different locations into nodes in a network that connects different places around the world. In essence, the Sónar festival has a FCE structure, but its innovation capacity is based on an additional dimension of the FCE, namely the relationships that allow the festival to establish a global network.

\section{The Festival's Relationships}

After analyzing the data obtained for this research, we can identify different kinds of relationships that are important to the role of Sónar as a FCE.

Many of the relationships that AM has developed over the years with artists, partners, and other stakeholders have grown along with the event. For example, Olaf Bender (manager of Level Raster Norton Germany, interviewed in 2009) suggested, "Since 10 years we are every time at (Barcelona) Sónar, and we have grown up with the festival. The festival has developed as the music sector, like us. At the beginning the festival was more experimental and grew up to more popular sounds." These relationships tend to evolve at the same pace as the festival itself, and on an equal, reciprocal basis. These relationships allow AM to establish trust and confidence in potentially interesting partners. In this group, we can place many long-term relationships the festival organization has with musicians, stakeholders, agents, or public administrations. This allows the festival to be connected permanently to the "space of flows" as well as being embedded in the "space of places” of the original eventful city, Barcelona.

Sónar exports its brand around the world through a strong collaboration with local partners in different locations around the world. The festival collaborates with local professionals who possess embedded local knowledge about the audience, the market, and the local music industry. This enables Sónar to identify appropriate strategies, logistics, and production as well as gathering knowledge on local musicians and the local music scene that form the basis for innovatory concepts.

These relationships thrive on the local context where the festival takes place and it is not surprising that the program is also influenced by the places where the festival has been held. For example, since the festival has been developing a SónarSound in Tokyo there have been more Japanese performances in the Barcelona program. These relationships with international partners facilitate staging the festival in other parts of the world, but they also generate a cascade of new relationships with local partners such as musicians, actors, managers, and audiences. Taglietti explained, "The connection with local partners helps us to understand the market and to ensure the success of the festival in other countries and places, but at the same time this partner should have the look and feel of our festival" (personal interview, 2013). In other words, in these relationships the global switchers from Sónar helping to knit together relationships with and between the programmers in the local "spaces of places" around the world.

Sónar also builds relationships that foster the development of the local music industry in the countries where the festival takes place. As one of the festival directors, Enric Palau commented, "sometimes you feel that the festival also enriches the local scene as you find artists from the same city at the festival who had not ever spoken before" (personal interview, 2010).

Therefore, it could be understood that the festival acts as a magnet for professionals who come together to exchange information in the local music scene. That means the festival generates knowledge circulation between professionals and provides a platform for local music sector development. As the Seoul artist Fortune Cookie commented, "I think we need a festival like this to help us create a local electronic music scene” (personal interview, 2010). The development of local relationships allows AM to act as a switcher, linking the local networks in the "space of places" with the "space of flows," helping to configure the local music industry. 
It can be seen that each type of relationship helps AM to configure the electronic music field on a global as well as a local level. Some relationships built up over time strengthen the knowledge base and help to establish Sónar as the place to be and be seen. Other relationships help to broaden the catchment area of Sónar and bring them into contact with new local partners who can establish a local version of the event. Finally, some other relationships help to spread how the field operates to new areas of the world, thereby helping to strengthen Sónar's position as knowledge leader in the field.

\section{The Festival's Innovation Role}

Innovation is often described as a process of doing something new, which firms often achieve through extensive interaction (Fagerberg, 2003), as well as a process with a specific focus on geographical distribution of knowledge (Martin \& Moodysson, 2010). Wijnberg (2004) also emphasized the role of value creation and competition in the selection system as important drivers of innovation.

The different kinds of relationships that Sónar has been developing over the years, as well as data collected from the interviews, lead us to observe that the festival in Barcelona generates interaction between professionals, artists, and audiences from different parts of the world, supporting the selection process. At the same time, the event distributes both codified and tacit knowledge (Bathelt et al., 2004), as some of the actors are embedded in the community and others are globally connected.

In this light, we can see that the Sónar festival, with its network of nodes in cities around the world and its central hub in Barcelona, uses its relationships to generate and distribute knowledge, which in turn develops value and competition in the electronic music field. In the general creative industries field in which Sónar operates, innovation is largely based on style and fashion. The festival uses all three of Tran's (2010) dimensions of stylistic innovation (symbolic value, the construction of this value through intersubjectivity, and timing), which lead us to identify Sónar as a stylistic innovative event. The festival in Barcelona generates symbolic value, which is increased through its network of events, which funnel international selectors and switchers to the Barcelona festival. By making copies of itself on a global scale, Sónar also increases the value of the Barcelona event as the "original" festival. Therefore, the Barcelona event becomes a spatial and temporal "hub" at which all the actors in the electronic music scene need to congregate in order to exchange knowledge and to establish their own position in that scene. In contrast, the other Sónar editions around the world are mere "nodes" in this global network, generally visited by the local actors organizing the event and the Sónar representatives from AM, who serve to validate the local version of the event.

Therefore, the Barcelona festival has an important role on the electronic music around the world, not just as a major commercial event, but also as a trend generator and innovation hub-a magnet for the selectors and switchers who can generate stylistic innovation. Sónar is not just a source of eventfulness in its home city of Barcelona, but in other cities around the world as well.

\section{Discussion}

In this article, we set out to analyze the development of a field configuring event over time. This specific field setting allowed us to build upon Lampel and Meyer's (2008) idea that field configuring events are not only mechanisms of field configuration but also products of a field, shaped by field developments in a recursive process.

In particular, our research points to an important difference between large-scale events that only occur once or at infrequent intervals (such as major political summits or the Olympic Games) and relatively regular and frequently-occurring events such as Sónar. Whereas major one-time events have the potential to generate momentum for a reordering of political positions, regular events seem more likely to support the establishment of interpersonal trust, which may lead to greater and more open knowledge circulation, thereby stimulating innovation more effectively. This mirrors the division suggested by Richards (2015) between "iterative" and "pulsar" events in cities. Regular iterative events help to feed the pool of creative talent and ideas at the level of cultural programming, whereas larger pulsar events provide the catalyst for transformation through the injection of new ideas and contacts with external selectors. 
Our analysis suggests that a festival such as Sónar can be a stimulus of stylistic innovation. The Barcelona festival influences the selectors, being a hub in the network, which the selectors have to pass through. As Osborne (personal interview, 2010) argued, the festival always attracts interesting artists and has new performances programmed, and therefore is an event where the selectors (Wijnberg, 2004) and switchers (Castells, 2009, 2010) need to have a clear idea what is actual "trendy" in the field or scene.

Sónar, founded in a certain place and developed in a particular historical context, enabled the organizers to connect with local trends in the production of electronic music and culture, in the "space of places.” Following Tran (2010), we also see the timing of Sónar as important, because it emerged at a time when the city of Barcelona was looking for new cultural and creative content to develop itself as an eventful city. As one of the first major festivals in its field, Sónar also managed to create a position for itself as the "original" event, even though it continued to spawn copies around the globe. Over the years, the festival also constructed an international network that allowed these local spaces to be connected to the "space of flows" in the electronic music field. Effectively we argue that Sónar, by establishing itself as a hub within a global network, has been able to innovate by taking a local product and introducing this to new global markets, eventually producing a "glocal" product.

The long-term stability of Sónar has generated an exchange of ideas with partners and the development of new models. This innovatory activity is supported by the fact that Sónar can always fall back on the hub, the origin to which all relationships return. In this sense, the role of Sónar as a FCE is very different from other events that rotate between different locations, such as the Olympic Games. Whereas the Olympics has to safeguard the "spirit" of the event and its commercial interests through extremely prescriptive guidelines, Sónar thrives on the local specificity that attaches to each new edition of the event and which helps in turn to maintain the edge of the original and the innovatory potential of the network. Whereas the original version of the Olympics lies in Ancient Greece and is seen as an unchanging, "authentic" model, the original Sónar Barcelona is still evolving and changing through its contacts with other eventful cities.

In the case of Sónar the link between the global "space of flows" and the local "space of places" is an important development of the eventful city model. Today, most cultural and economic fields are global, so it is almost inevitable that an event based in a specific local context will also have a relationship with the global "space of flows." The extent to which a particular event can configure the global field will depend on the significance that it can give to the "space of places" in which it takes place. In the case of Sónar at least, maintaining the relevance of the local space of Barcelona to the global electronic music scene has depended heavily on the ability of the festival to innovate and stay ahead of trends.

Therefore, the evidence we have reviewed here seems to suggest that Sónar plays an important role as a source of eventfulness in different cities, as well as being an innovative hub for its field. Therefore, in answer to our research question we can say that a FCE such as the Sónar festival can act as a stimulus for innovation and eventfulness by fulfilling a hub function within a global network. The hub is the spatial and temporal point through which those involved in the selection of stylistic innovations must pass, a process that affirms the position of the selectors and other nodes in the network as well as the central innovation function of Sónar. In this way, the “selector" function identified by Wijnberg (2004) as being crucial to stylistic innovation processes also converges with the "switcher" role described by Castells (2009), which is vital to the linkage of global and local networks.

During this research, we identified some limitations. Most importantly, we focused on one specific and in many ways unique transnational event, and so our findings may not be directly applicable to other fields, events, or cities. It would be interesting to analyze other creative industries events in order to see if FCE in other creative fields are also able to act in a similar way. In contrast to much previous FCE research, the Sónar festival is also a commercial event, and we do not know to what extent commercialization affects the ability of other FCEs to generate innovation.

In spite of these limitations, our research seems to indicate that the globalization of event formats 
and concepts can stimulate innovation, influencing other events or products in wider networks and affecting the role of selectors in identifying new trends, ideas, and products.

\section{Notes}

${ }^{1}$ Some of these in-depth interviews were conducted between 2009 and 2010 in the framework of the European financed research project EURO Festivals Arts Festivals and European Public Culture (Giorgi, 2010).

${ }^{2}$ During the 1980s, Caballero and Palau ran an electronic music and performative band called Jumo, and in 1992 worked together as curators for the electronic music and experimental art for the Spanish Pavilion on the World Fair Expo'92 in Seville.

${ }^{3}$ At that moment, Robles was involved on the electronic music and vanguard culture underground scene, working for the counter-culture magazine Ajoblanco, published between 1974 and 1999.

${ }^{4}$ The SGAE (General Society of Authors and Publishers) is the Spanish national creator's association with the aim of organising copyright issues.

${ }^{5}$ The CCCB is a cultural institution in the centre of Barcelona, inaugurated in 1994, created as a multidisciplinary institution dedicated to the study of cities and urban culture. It is constituted as a consortium formed by the city council of Barcelona and the Barcelona Provincial Council. It stages exhibitions related to contemporary urban culture as well as related events and festivals.

${ }^{6}$ Interviews held between 2009 and 2010 by A. Colombo in Barcelona in the framework of the EU FP7 funded research project EuroFestival.

${ }^{7}$ Data obtained by the Sónar Festival website 2009.

\section{References}

Anand, N., \& Jones, B. C. (2008). Tournament rituals, category dynamics, and field configuration: The case of the Booker prize. Journal of Management Studies, 45(6), 1036-1060.

Anand, N., \& Watson, M. R. (2004). Tournament rituals in the evolution of fields: The case of the Grammy Awards. Academy of Management Journal, 47(1), 59-80.

Bernárdez, J. (2011). Caso: Sónar, el Festival Internacional de Música Avanzada y Arte Multimedia de Barcelona. Retrieved from https://www.slideshare.net/JorgeBernardez/ caso-sonar-el-festival-internacional-de-msica-avanzaday-de-arte-multimedia-de-barcelona-v-espaol-dic-2012

Bathelt, H., Malmberg, A., \& Maskell, P. (2004). Clusters and knowledge: Local buzz, global pipelines and the process of knowledge creation. Progress in Human Geography, 28(1), 31-56.

Castells, M. (2009). Communication. Power. Oxford, UK: Blackwell.

Castells, M. (2010). The rise of the network society. The information age: Economy, society and culture, Volume I. Malden, MA: Wiley-Blackwell.
Castells, M. (2012). Networks of outrage and hope. Social movements in the internet age. Cambridge, UK: Polity Press.

Cohendet, P., Grandadam, D., \& Simon, L. (2010). The anatomy of the creative city. Industry \& Innovation, 17, 91-111.

Colombo, A. (2009). Expansive waves of festivals: Approaches in economic impact studies of arts festivals. La revista d'economia della cultura, 3, 351-358.

Crespi-Vallbona, M., \& Richards, G. (2007). The meaning of cultural festivals. International Journal of Cultural Policy, 13(1), 103-122.

Czarniawska, B., \& Sevón, G. (2005). Global ideas. How ideas, objects and practices travel in the global economy. Malmö, Sweden: Copenhagen Business School Press.

Evans, G. (2003). Hard-branding the cultural city-from Prado to Prada. International Journal of Urban and Regional Research, 27, 417-440.

Evans, G. (2007). Branding the city of culture-the death of city planning? In J. Monclús \& M. Guàrdia (Eds.), Culture, urbanism and planning (pp. 197-214). Aldershot, UK: Ashgate.

Fagerberg, J. (2003). Innovation: A guide to literature. In J. Fagerberg \& D. C. Mowery (Eds.), Oxford handbook of innovation (pp. 1-31). Oxford, UK: Oxford University Press.

Ferdinand, N., \& Williams, N. L. (2013). International festivals as experience production systems. Tourism Management, 34, 202-210.

Font, J., \& Salat, \& J. M. (2007). Sónar around the world. Documentary produced by TV3-Televisió de Catalunya.

García, B. (2004). Urban regeneration, arts programming and major events: Glasgow 1990, Sydney 2000 and Barcelona 2004. International Journal of Cultural Policy, 10, 103-118.

García, B., Melville, R., \& Cox, T. (2010). Creating an impact: Liverpool's experience as European capital of culture. Liverpool, UK: Impacts 08.

Getz, D. (1991). Festivals, special events and tourism. New York, NY: Van Nostrand Reinhold.

Giorgi, L. (2010). European arts festivals. Cultural pragmatics and discursive identity frames. Eurofestival Project, European Arts Festivals and Public Culture, Project 215747, SSH-2007-5.2.2 "Creativity, Culture and Democracy.” EU: Seventh Framework Programme.

Hardbord, J. (2002). Film cultures. London, UK: Sage.

Häusserman, H., \& Siebel, W. (1993). Festivalisierung der Stadtpolitik: Stadtentwicklung durch grosse Projekte. Opladen, Germany: Westdeutscher Verlag.

Jakob, D. (2012). The eventification of place: Urban development and experience consumption in Berlin and New York City. European Urban and Regional Studies, 20(4), 447-459.

Lampel, J., \& Meyer, A. D. (2008). Field-configuring events as structuring mechanisms: How conferences, ceremonies, and trade shows constitute new technologies, industries, 
and markets. Journal of Management Studies, 45(6), 1025-1035.

Lash, S., \& Urry, J. (1994). Economies of signs and space. London, UK: Sage

Magaudda, P. (2009). The history of the Sonar Festival. In J. Segal \& L. Giorgi (Eds.), European arts festivals from a historical perspective. Research Report D2, Eurofestival Project, European Arts Festivals and Public Culture, Project 215747, SSH-2007-5.2.2 “Creativity, Culture and Democracy.” EU: Seventh Framework Programme.

Magaudda, P., \& Colombo, A. (2010). The Sónar festival. In J. Segal, \& L. Giorgi (Eds.), European arts festivals. Cultural pragmatics and discursive identity frames. Eurofestival Project, European Arts Festivals and Public Culture, Project 215747, SSH-2007-5.2.2 “Creativity, Culture and Democracy.” EU: Seventh Framework Programme.

Martin, R., \& Moodysson, J. (2010). Innovation in symbolic industries: The geography and organization of knowledge sourcing. European Planning Studies, 19(7), 1183-1203.

Miles, M. B., Huberman, A. M. \& Saldaña, J. (2013). Qualitative data analysis: A methods sourcebook. London, UK: SAGE.

Nijman, J. (1999). Cultural globalization and the identity of place: The reconstruction of Amsterdam. Ecumene, 6, 146-164.

Oliveras, J. (2008). Sónar-Festival Internacional de Música Avanzada y Arte Multimedia de Barcelona. In A. Colombo \& D. Rosselló (Eds.), Gestión Cultural: Estudios de Caso. Barcelona, Spain: Ariel.

Potts, J., Cunningham, S., Hartley, J., \& Ormerod, P. (2008). Social network markets: A new definition of the creative industries. Journal of Cultural Economics, 32, 167-185.

Richards, G. (2015). Events in the network society: The role of pulsar and iterative events. Event Management, 19(4), 553-566.

Richards, G., \& Palmer, R. (2010). Eventful cities: Cultural management and urban revitalisation. London, UK: Routledge.

Robertson, R. (1990). Mapping the global condition: Globalization as the central concept. Theory, Culture \& Society, 7(2-3), 15-30.

Rovira, E. (2010). BCN how are you? MA Thesis in Leisure Studies, Tilburg University, Tilburg, Netherlands.

Schüßler, E., \& Sydow, J. (2013). Organizing events for configuring and maintaining creative fields. In C., Jones, M. Lorenzen, \& J. Sapsed (Eds.), Oxford handbook of creative industries (pp. 284-300). Oxford, UK: Oxford University Press.

Tran, Y. (2010). Generating stylistic innovation: A process perspective. Industry and Innovation, 17(2), 131-161.

UNESCO. (2013). Creative economy report. Paris, France: Author.

Waitt, G. (2003). Social impact of the Sydney Olympics. Annuals of Tourism Research, 30(1), 194-215.

Waitt, G. (2008). Urban festivals: Geographies of hype, helplessness and hope. Geography Compass, 28(2), 513-37.

Wijnberg, N. M. (2004). Innovation and organization: Value and competition in selection systems. Organization Studies, 25(8), 1413-1433.

Yin, R. K (2004). Case study research, design and methods. London, UK: Sage. 
Copyright of Event Management is the property of Cognizant, LLC and its content may not be copied or emailed to multiple sites or posted to a listserv without the copyright holder's express written permission. However, users may print, download, or email articles for individual use. 